\title{
UBERABA - ESPAÇO URBANO NO CONTEXTO BRASILEIRO
}

\author{
UBERABA - URBAN SPACE IN THE BRAZILIAN CONT
}

\author{
Edna Aparecida de Carvalho Pacheco ${ }^{1}$
}

RESUMO: Este artigo pretende mobilizar reflexões sobre a construção do espaço urbano da cidade de Uberaba MG enquanto unidade federativa do contexto brasileiro localizado na região conhecida como Triângulo Mineiro. A construção do argumento remete à práxis dos sujeitos sociais atores da construção coletiva que resulta na materialização do espaço cotidiano de manifestações culturais, econômicas e sociais que apresenta identidade significativa para o contexto das relações regionais. A cultura, enquanto categoria teórica auxilia na argumentação reflexiva, vinculada ao resgate da historicidade do fenômeno, com vistas à configuração do espaço urbano característico das sociedades industriais na modernidade. O cenário sócio político regula e mobiliza as relações no urbano, mediatizados por relações de produção capitalistas que sustentam e renovam a dinâmica urbana. Resulta-se na indicação teórica da cidade mineira com as características próprias e comuns ao que denomina sociedade urbana moderna. O estado enquanto mediador das relações entre capita versus trabalho é reconhecido como elemento que exerce suas funções e atribuições com clara opção e pautadas nos interesses do capita. Há, portanto fortes indicações que de que o urbano Uberaba configura espaço de relações sociais produtoras de cultura, de mercadorias, de capital e, segregação social, o que não o difere de outras realidades no contexto brasileiro.

Palavras-chave: Mobilização. Espaço Urbano. Sociedade.

ABSTRACT: This article aims to mobilise reflections on the construction of the urban space of the city of Uberaba MG while the Federal Brazilian context unit located in the region known as Triângulo Mineiro. The construction of the argument refers to the praxis of social actors of collective construction that results in the materialization of everyday space of cultural, economic and social rights that introduces significant identity to the context of regional relations. Culture, while category theoretical argumentation assists in reflective, linked to the rescue of the historicity of the phenomenon, with views to the configuration of urban space characteristic of societies industrial modernity. The social and political scenario regulates and mobilizes the relationships in urban, practical by capitalist production relations that sustain and renew the urban dynamics. Results in theoretical indication of mining town with its own characteristics and common styling modern urban society. The State as a mediator of relations between capita versus working is recognized as an element that carries out its functions with clear option and guided us interests of capita. There are therefore strong indications that the urban Uberaba configures space of social relations culture, producing goods, capital, and social seregação, which doesn't differ from other realities in the Canadian context.

Keywords: Mobilizatio. Urban Spac. Society

${ }^{1}$ Doutora em Serviço Social pela UNESP de Franca-SP, vice- coordenadora de Estágio Supervisionado e docente do Curso de Serviço Social da Universidade Federal do Triângulo MineiroUberaba - MG. 


\section{ANTECEDENTES DA CONSTRUÇÃO DO FENÔMENO URBANIZAÇÃO}

Cada localização é, pois, um momento do imenso movimento do mundo, apreendido em um ponto geográfico, um lugar. (SANTOS, 1997, p.2)

Pensar o espaço das cidades requer uma concentração numa imagem particular de desenvolvimento espacial urbano que configura as cidades. A produção do espaço regional envolve o Estado tanto quanto a economia, pois aquele regulamenta, incentiva as relações econômicas, bem como define a ocupação do espaço urbano através, por exemplo, das definições das diretrizes constantes no plano diretor da cidade.

O alinhamento histórico da configuração da região mineira onde se situa a cidade de Uberaba aparece aqui como forma organizada para mobilizar a reflexão teórica sobre a o aparecimento e dinâmicas dos espaços urbanos caracterizado e reconhecido como a cidade mineira constituinte do Triângulo Mineiro; Uberaba.

.Etinograficamente a origem do nome da cidade é resultado da expressão Tupi-Guarani V-Berab-a, que significa água brilhante ou água que brilha.

A região que é hoje denominada Triângulo Mineiro era conhecida no período colonial e até meados do século XIX como Sertão da Farinha Podre, e compreendia todas as terras situadas entre os rios Quebra Anzol, Das Velhas (hoje Araguari), Grande e Paranaíba.

Até 1748 fazia parte da Capitania de São Paulo; entre 1748 e 1816 pertenceu a Capitania de Goiás e desta data em diante constituiu a Capitania e, depois Província de Minas Gerais.

O município de Uberaba, segundo fontes históricas, compreendia quase a totalidade das terras da região denominada Triângulo Mineiro. Nasceu na beira de uma estrada que Anhanguera - o português Bartolomeu Bueno da Silva, construiu na suas entradas pelo sertão em busca de ouro.

A Via Anhanguera, símbolo da dominação e desenvolvimento econômico, atravessa o Triângulo de sul a norte do porto de Santos a Uberaba e daí para Goiás e Cuiabá.

A Guerra do Paraguai em 1856 e o bloqueio do Rio da Prata desviando 
o trânsito em direção a Mato Grosso para Uberaba são fatos históricos que precisam ser lembrados para explicar a ampliação da atividade comercial de Uberaba. Em função dessa providência que tinha objetivos políticos, a atividade comercial se constituiu na atividade mais importante, durante a segunda metade do século XIX.

A síntese cronológica com fatos importantes para a compreensão da configuração do espaço geográfico e político de Uberaba compõe um tempo histórico e marca as realizações dos sujeitos sociais em um determinado espaço, como por exemplo:

13.02.1811- Criado o Distrito dos Índios de Santo Antonio de Uberaba

02.03.1820 -Elevação a Freguesia (arraial)

22.02.1836- Elevação a Vila

23.03.1840- Elevação à condição de Comarca do Rio Paraná

02.05.1856- Elevação à condição de cidade, retirando-se parte do nome anterior para ficar apenas Uberaba

12.11.1878- Mudança de denominação da Comarca do Paraná para Comarca de Uberaba

Reconhecida mundialmente pela excelência, na criação com utilização de tecnologias de ponta do gado zebu e ocupando posição de destaque nacional nas relações comerciais, com base na agropecuária, a cidade de Uberaba é expressão contraditória do modelo de acumulação capitalista.

A infra-estrutura necessária ao desenvolvimento econômico está marcada pelo pioneirismo do local que inaugurou iluminação elétrica na abertura do século, em 1905.

A exploração do potencial energético do Rio Grande garante, até hoje, o abastecimento e empreendimentos nesse setor que totaliza 14 usinas hidrelétricas na região.

A cidade de Uberaba destaca-se como centro educacional: na década de 1950 foi criada a Faculdade de Medicina do Triângulo Mineiro, instituição significativa na formação de profissionais da área que exercem a profissão em todo o território nacional. ${ }^{2}$

A década de 1970 foi marcada pelo incremento no processo de

\footnotetext{
2 A Faculdade de Medicina do Triângulo Mineiro - FMTM, fundada em 1953, foi transformada em Universidade Federal do Triângulo Mineiro - UFTM, no ano de 2005. A Instituição é reconhecida entre as melhores, com a 3를 colocação de Minas Gerais e a 6 ${ }^{\underline{a}}$ do País.
} 
industrialização do município; ampliação do parque industrial com a diversificação das atividades fabris mantendo, no entanto, vínculo com a vocação da região na utilização de matérias primas local e o direcionamento para empreendimentos da atividade agropecuária no país.

A cidade é pólo industrial de fertilizantes produzindo trinta por cento do fertilizante fosfatado do país, corretivos, defensivos e equipamentos. Para a pecuária produz sêmem e embriões, mantém indústrias de laticínios, com penetração significativa no mercado internacional, e curtumes, inclusive com o despontar da fabricação de botinas comercializadas em diversos pontos do país.

As cidades brasileiras têm sua gênese há mais de quatrocentos anos quando os exploradores portugueses começaram a chegar em busca de riquezas; primeiro as matas do litoral foram exploradas em busca do pau-brasil, que culminaram nas primeiras aglomerações que deram origem as primeiras cidades.

A agricultura do açúcar, do algodão e do café e, posteriormente, a criação de gado aparecem como destaque de atividades econômicas do país que impulsionaram a ocupação do solo brasileiro pelos portugueses.

As cidades do interior surgem com o movimento dos bandeirantes e sesmeiros que desbravam caminhos pelo interior da colônia em busca de riquezas e novas terras, provocando o surgimento de novas vilas e povoados.

Em Minas Gerais, as cidades interioranas nasceram principalmente em razão da extração de minerais, especialmente o ouro. Assim as primeiras vilas aparecem durante os séculos XVII, XVIII e XIX e hoje são conhecidas como as cidades de Ouro Preto, Sabará, Diamantina, Mariana, São João Del Rei e Tiradentes, neste período representavam a rota do ouro.

Gilberto Velho em seu livro Individualismo e cultura (1987) faz uma interessante conexão entre a hierarquização da sociedade brasileira e a colonização portuguesa.

Para o autor o próprio processo de colonização que ocorreu em um momento em que o Renascimento e a Reforma, com seus respectivos correlatos, já definiram um sistema cultural em que o individualismo - enquanto ideologia inovadora em relação ä Idade Média pragmática já havia se infiltrado nos sistemas mais totalitários - constrói situações diversificadas.

Por exemplo, desenvolve-se uma sociedade em que a hierarquia é o 
princípio ordenador: no modo de produção apoiado pelo trabalho escravo constituído por categorias sociais de valores desiguais onde, de um lado, estão os senhores de engenho, mais tarde os usineiros e, do outro lado, os escravos, depois os proletários rurais e urbanos, ficam muito parecido com as sociedades de castas.

No entanto, em outras áreas do país a sociedade organiza-se de modo diferente como no caso das entradas e bandeiras, os ciclos do ouro e do gado e a contínua expansão das fronteiras internas abrem espaço para uma ideologia e uma escala de valores onde o indivíduo pode ser a unidade social significativa, dependendo, é claro, de uma ação legitimadora do Estado que, com mecanismos limitadores, pode impedir ou estimular "surtos individualistas".

O Estado de Minas Gerais com os Ciclos do Ouro e dos Diamantes criou uma sociedade com indícios particularizantes manifesto na literatura, música, artes plásticas entre outros.

A cultura particularizada do povo mineiro que se auto classifica como pacíficos enquanto construtores de uma história de poucas guerras, com poucos, mais importantes nomes de expressão na luta pelo direito de ser brasileiro num território dominado por estrangeiros e, ou, ideais fundamentados na segregação, como Tiradentes e o ideal republicano.

Mas também um povo que se destaca desde as capitanias como especialista no trato com as questões agrárias, daí o senso comum de que o mineiro é "caipira" no sentido da relação com o rural.

As manifestações culturais demonstram um senso crítico carregado de humor que ilustram a perspicácia e ousadia do mineiro.

A síntese dessa idéia pode ser lida em "causos" contados por um autor mineiro que relata em textos muito bem humorados a história cultural do seu povo, contextualizando e indicando características próprias.

A literatura ressalta o uberabense como um sujeito convicto, conceituado como "misto de mineiro, paulista e goiano, portanto um tipo diferente, tradicional e conservador nos costumes, mas revolucionário nos hábitos. A transcrição de um dos seus causos colhidos no livro $O$ triângulo de bermudas (CUNHA,2001.)

O título, de modo sutil, satiriza a configuração geográfica onde está situada a cidade de Uberaba, anuncia, a partir do olhar de um mineiro, algumas características culturais e o modo de expressá-las: 


\section{Buscando Certeza}

Uma das mais apreciáveis características do nosso povinho é a discrição, que ele exerce freqüentemente em regime de autoproteção. Embora paulista-agente, o triangulino é mineiro-vivente-não se mostra, esconde o jogo, assunta, observa, vigia. Fubá é o nome do Camilo Nunes. Na realidade é apelido, mas nos invernistas do Triângulo, Barretos e Araçatuba pouca gente sabe disso, ou do seu nome de batismo. Tremendo conhecedor de gado e gente, Fubá fez nome pelo seu espírito, inteligência, senso de humor, sorriso pronto, fala mansa de mineirinho caipira em conduzir negócio a final feliz-sempre a seu favor. Apesar disso, e como tantos outros, Fubá quebrou na Uberaba do Zebu de ouro e foi obrigado, como todos, a emigrar para novas terras e negócios. Baixou em Araçatuba, inicio da era de corte, mais quebrado que arroz de terceira e mais animado que galo de briga no primeiro encosto. A barra foi dura, viajando no fordinho, comprando bezerros fiados pra vender aos invernistas mais ricos e acomodados, morando em hotelzinho de segunda, fazendo tempo e esperança de levar a Marina de Minas pra lá.Um dia, a sorte estourou, e no sentido real. Fubá e o primo Zé tinham comprado um bilhete da federal, no sair da manhã e da luta diária. Voltaram ä tardinha, Araçatuba em festa, foguetório promovido pelo dono da lotérica: a sorte grande tinha saído ali. Diziam pela rua que dois mineiros eram os felizardos. Zé, tímido e assustado, aguardou a decisão de Fubá, ainda incerto se eram eles os felizardos premiados.Fubá escorregou pela rua até o ajuntamento na casa vendedora, todo mundo feliz e aguardante. Pasmou ali uns minutos, escutando o papo, aproximando-se do falante e esfuziante vendedor.Chega um curioso e pergunta: - Afinal, quem foi que comprou a sorte? E o dono, enfunado nos seus ventos: - Tou esperando eles. São dois caipiras mineiros, rabo-grosso, lá de Uberaba. Sorte só sai pra gente atrasada! Fubá escorreu de volta ao hotelzinho e ao Zé disparou a conclusão: - Zé, ganhamos mesmo! (CUNHA, 2001, p.104-105).

\section{INDIVÍDUO, CULTURA E A CONSTRUÇÃO DA REALIDADE REGIONAL}

Um dos aspectos importantes assimilados da discussão antropológica está no risco metodológico de que ao se isolar, por motivos de estratégia de pesquisa, ou outros estudos, segmentos ou grupos sociais e tomá-los como realmente independentes é ilusório, porque grupos aparentemente isolados podem fazer parte de um sistema mais amplo em termos econômicos, políticos e culturais.

Certamente, identificar sociedades tribais ou complexas exige a adoção de critérios determinantes que definam a sua unidade ou homogeneidade para se falar em menor ou maior complexidade.

A dimensão complexa traz a idéia de heterogeneidade cultural entendida como a coexistência, harmoniosa ou não, de uma pluralidade de tradições com base ocupacional, étnicas, religiosa e outras.

É, portanto, importante verificar quando e como as diferenças culturais 
de uma sociedade complexa explicam a divisão social do trabalho, pois existe uma relação intrínseca entre essas duas dimensões; a divisão social do trabalho e a heterogeneidade cultural, ou seja, como a divisão social do trabalho explica as diferentes tradições culturais de uma sociedade?

Entende-se nossa sociedade como complexa industrial, resultante da Revolução que moldou um tipo de sociedade, cuja complexidade está fundamentalmente relacionada a uma acentuada divisão social do trabalho, ao aumento da produção e do consumo, à articulação do mercado mundial e a um rápido e espantoso crescimento urbano.

Este tipo de sociedade abarca um número maior de indivíduos em razão das forças produtivas (conjunto social da tecnologia de produção) que proporcionou o crescimento populacional e baixou o nível de mortalidade, configurando a principal característica da sociedade industrial complexa; o aparecimento das cidades habitadas cada vez mais por um maior número de pessoas que usufruem das inovações tecnológicas como sistema de transporte e recursos e organização da produção.

As cidades modernas e o espaço que se está ocupando podem ser entendidos na perspectiva de Bosi (1992), a partir da identificação das marcas culturais presentes.

O verbo latino Colo dá sentido à ação de ocupar a terra, trabalhar, cultivar a terra; é expressão maior de um movimento sempre incompleto, portanto, transitivo, na perspectiva de que o ato ou fenômeno contém possibilidades de sujeição do agente que depende do trabalho para sobreviver.

A ocupação do solo urbano configura a reprodução do projeto de colonização do "Novo Mundo", num arremedo de projeto cujas forças motrizes são buscadas em nível da ocupação da terra, ou seja, morar em determinado pedaço de terra.

Embora os agentes deste processo não são apenas suportes físicos de operações econômicas, como os exploradores europeus, mas sim sujeitos sociais que trazem na memória, na linguagem, e na identidade traços culturais que serviram de armas, escudo, estímulo, incentivo nas lutas cotidianas pela sobrevivência.

Para o antropólogo especialista em questões urbanas Gilberto Velho, em toda e qualquer sociedade em princípio existe a possibilidade de individualização, processo que não se dá fora das normas e padrões daquela 
sociedade, por mais valorizada que seja a liberdade individual.

A noção de que os indivíduos têm capacidade para efetivar escolhas é a base para se pensar em projetos.

Na tentativa de individualização no contexto antropológico para explicar a cultura, o autor trata de projetos como fenômeno puramente interno, subjetivo, elaborado dentro de um campo de possibilidades, circunscrito histórica e culturalmente, onde o ator vive a sua experiência como única se reconhecendo nos outros através das semelhanças e coincidências.

O projeto enquanto conjunto de idéias e, conseqüentemente, as condutas que compõem o processo de execução estão sempre referidos a outros projetos

As cidades que, no passado, representavam a forma compacta de um processo histórico em formação, na atualidade, a população urbana encontra-se distribuída e organizada em áreas regionais em permanente expansão que é amorfa na forma, maciças no propósito e hierárquicas na sua escala de organização social.

A cidade moderna apresenta características precisas como espaço de concentração populacional, de instrumentos de produção, de capital, de necessidades e prazeres. A cidade é lócus privilegiado de produção do conhecimento, de obras, alegria, prazer e, de coisas objetos (bens materiais trocáveis), espaço ocupado por todo tipo de gente e atividades, ou seja, uma sociedade.

Essa configuração social indica a necessidade de uma administração, de polícia, de impostos, ou seja, de política voltada para a realização do bem comum através das organizações e instituições públicas e privadas.

Dentre as várias instituições existentes nas sociedades capitalistas destacam-se as instituições de ensino, responsáveis pelo processo formativo de líderes pensantes capazes de desencadear ação construtiva nas diferentes áreas de conhecimento que, integradas, constituem o patrimônio cultural da espécie.

As divisões entre campo e cidade imprimiram uma digressão na noção de totalidade social: à cidade as atribuições do trabalho enriquecido e desenvolvido pelo trabalho intelectual, inclusive as funções de administrar e comandar; ao campo o trabalho material desprovido de inteligência. Evidentemente o progresso tecnológico do mundo contemporâneo tem definido outros contornos para essa realidade. 
A cidade sujeito coletivo da história responsável pelo global, pela práxis no seu conjunto é o cenário da produção criativa de estratégias ideológicas de intervenção administrativa e de condução do uso do solo urbano. .

A acumulação capitalista mercantil se materializou nos últimos quatro séculos. No entanto, na sua gênese (século XVI) se funda como localização privilegiada de produção explorando os trabalhos escravos, compulsórios, cuja base ou sede era o campo, mas o controle era efetivado no espaço urbano, estratégia econômica adotada para garantir a acumulação internacional.

Desse modo, as cidades assumem, no Brasil, um caráter políticoadministrativo marcado por uma estrutura burocrática e figurando como instrumento regulador da exploração mercantil. Destituídas da condição de mercado consumidor (uma vez que o produzido no campo era destinado à exportação) e, da força de trabalho.

Todo o processo histórico que determina o urbano no Brasil perpassa pela relação capital - Estado - modo de produção.

È evidente a simbiose Estado e classe social detentora dos bens de produção e o fundamental papel estatal na garantia da expansão capitalista, redundando na urbanização da economia e da sociedade e, é neste sentido, que se estabelece o que está definido como urbano.

O espaço estruturado pelo processo de urbanização - as cidades que concentram hoje, a indústria, o comércio, os serviços, níveis produtivos - orienta a classificação dos centros urbanos em pólos centrais e pólos periféricos, do ponto de vista econômico.

A análise do processo de desenvolvimento urbano mostra que o ritmo foi muito mais rápido e que há uma distinção significativa das necessidades socioeconômico e culturais das populações constituintes da classe trabalhadora, e que $\mathrm{o}$ atendimento dessas necessidades está subordinado às exigências da reprodução e acumulação capitalista, ou seja, as necessidades relativas à habitação, transporte, saúde, educação, assistência.

A segregação urbana é passível de compreensão através do mecanismo próprio do mercado imobiliário e do papel do Estado que, ao definir as regras gerais do desenvolvimento urbano e financiar os equipamentos coletivos, favorece os monopólios.

A especulação imobiliária é um fenômeno próprio do mercado e 
estruturador do modo de produção capitalista que permite a acumulação desigual e a conseqüentemente segregação social.

A realidade urbana concentra no espaço (cidade) e no tempo, os elementos da produção: as empresas, os mercados, as informações e as decisões. A sociedade capitalista urbanizada se funda na divisão social do trabalho e as cidades têm um papel preponderante para contribuir no crescimento das forças produtivas, da produtividade do trabalho, na utilização das técnicas.

Contraditoriamente, combinação das técnicas e a organização do trabalho têm produzido o aumento da população urbana, provocando o desaparecimento do campo.

O capitalismo e o seu modo de produção impõem a segregação de pessoas, de grupos, das funções e dos lugares. Essa imposição pode ser observada na contradição singular envolvendo a cidade e o campo: as cidades absorvem o campo estendendo o seu espaço físico, contraditoriamente a segregação capitalista produz a ruralização das cidades produzindo os subúrbios e as periferias, próximas ou distantes, que manifestam as conseqüências da propriedade da terra: especulação fundiária, rarefação espontânea ou provocada.

A cidade de Uberaba-MG tem $45 \%$ da sua economia representada pela industrialização da tradição local pecuarista. É palco de significativa produção de fertilizantes, de industrialização de produtos alimentícios; é espaço produtivo que criado a partir da produção agropecuária transformou-se em locus de industrialização urbana. É também reconhecida como centro produtor de móveis industrializados.

De modo muito simples poderia dizer que a urbanização é processo histórico concretizado pela ação do homem buscando novos rumos, novas perspectivas amparadas pelo ideal de desenvolvimento de progresso sob a égide das determinações do sistema capitalista.

\section{REFERÊNCIAS}

ACSELRAD, Henri (Org.). A duração das cidades: sustentabilidade e risco nas políticas urbanas. Rio de Janeiro: DP\&A, 2001.

ADAM, Kuper. Cultura: a visão dos antropólogos. Bauru, EDUSC, 2002 - (Coleção ciências sociais). 
BERGER, p. Curmann. A constituição social da realidade. Petrópolis: Vozes, 1985 BRITTO, L. N. Política e espaço regional. São Paulo: Nobel, 1986.

CHAUI, M. Cultura e democracia. São Paulo: Cortez, 1990, p. 39-60.

CUNHA, João Gilberto Rodrigues. 0 triângulo de bermudas: causos e estórias do triângulo mineiro, São Paulo: Peirópolis, 2001.

HARVEY, David. A justiça social e a cidade. São Paulo: Hucitec, 1980.

LARAIA, Roque de Barros. Cultura: um conceito antropológico. 16. ed. Rio de Janeiro: Zahar, 2003.

OLIVEIRA, Francisco. O Estado e o urbano. Espaço e debates. São Paulo: Cortez, n.6, p. 36-84, 1982.

PONTES, Hildebrando. História de Uberaba e a civilização no Brasil Central. Academia de Letras do Triângulo Mineiro, Uberaba,1970.

SINGER, Paul. Economia e política de urbanização. 2. ed. São Paulo: Brasiliense, 1975.

VELHO, Gilberto. Individualismo e cultura: notas para uma antropologia da sociedade contemporânea. 4. ed. Rio de Janeiro: Zahar, 1981. 